ARCHIVOS

de historia del movimiento obrero y la izquierda
ISSN 2313-9749

ISSN en línea 2683-9601

Año VIII, $n^{\circ} 16$, pp. 93-110

marzo de 2020-agosto de 2020

\title{
"Chicas como tú"... \\ Género, clase y trabajo en la Argentina reciente: un balance desde la historia social
}

\section{Andrea Andújar y Débora D’Antonio}

Consejo Nacional de Investigaciones Científicas y Técnicas - Instituto de Investigación de Estudios de Género - Universidad de Buenos

Aires (Argentina)·andreaandujar@gmail.com
Consejo Nacional de Investigaciones Científicas y Técnicas • Instituto de Investigación de Estudios de Género - Universidad de Buenos

Aires (Argentina)·deboradantonio@hotmail.com

Titulo: "Girls Like You"... Gender, Class and Labor in Recent Argentine: a Balance from Social History

Resumen: En este artículo nos proponemos repasar las principales contribuciones que brindan los cruces entre las categorias de clase y género al conocimiento de la historia de la clase trabajadora en el pasado reciente argentino contemplando el lugar de las mujeres. Guian el desarrollo de esta revisión preguntas tales como: ¿cuáles han sido los principales problemas y tópicos que se examinaron?; ¿qué esfuerzos teórico-metodológicos comportó tal empresa? y ¿qué dimensiones y aristas aún permanecen inexploradas?

Palabras clave: clase trabajadora - género - historia reciente

\begin{abstract}
In this article our proposal is to review the principal contributions that link the categories of class and gender that allows us to rebuild the history of the working class in the recent past, centrally considering the women's role. This work is guided by questions such as: which have been the principal problems and matters that were examined? What theoretical and methodological endeavors did such a company involve? And, what dimensions and edges are still unexplored?
\end{abstract}

Keywords: working class - gender - recent history

Recepción: 20 de diciembre de 2019. Aceptación: 27 de febrero de 2020 


\section{Introducción}

En las últimas décadas, la historia de las mujeres y los estudios de género han crecido sensiblemente en la Argentina gracias al sostenido empeño de un conjunto de historiadoras comprometidas con el feminismo o el movimiento de mujeres. Pertenecientes a distintas generaciones, con diversas trayectorias políticas y preferencias teóricas en su haber, estas investigadoras han puesto en cuestión el androcentrismo del quehacer disciplinar demostrando la incidencia de las mujeres y su agencia en el decurso social, la historicidad de los significados de la diferencia sexual y la desigualdad que opera en esa diferencia, así como su gravitación en el proceso histórico. La concreción de ese logro exigió variadas estrategias metodológicas y elaboraciones conceptuales dispuestas a eludir, entre otras cosas, la reificación de las mujeres en el lugar de víctimas o heroínas para reponerlas como sujetos que, lejos de conformar un universo homogéneo, ponían en disputa aspectos parciales o totales de la sociedad en que les tocó vivir a la luz de su pertenencia de clase, étnica, racializada o generacional.

El desarrollo de esta perspectiva histórica aborda un amplio abanico de tópicos, interrogantes y problemas en los que el mundo de la política, el de la cultura y el del trabajo tienen en cierta medida la delantera. Es sobre este último donde este artículo cifra su interés, proponiéndose revisar los aportes brindados por los cruces entre clase y género para la reconstrucción de la historia de la clase trabajadora en la Argentina reciente. Cuáles han sido los principales problemas y tópicos que se examinaron; qué líneas históricas se destacaron; qué esfuerzos teórico-metodológicos comportó tal empresa; qué dimensiones y aristas aún permanecen inexploradas o escasamente visitadas son algunas de las preguntas que enmarcan el cometido de las páginas que siguen. Su apuesta es demostrar, como lo advirtió hace tiempo Catherine Hall (2013), que la perspectiva feminista es cardinal para comprender más acabadamente la historia de la clase trabajadora al revelar la determinación estructural del género en la edificación de la identidad de clase $y$, por tanto, en la manera en que varones y mujeres experimentaron sus condiciones materiales de existencia, se organizaron y confrontaron con sus adversarios de clase y entre sí, en demanda por derechos.

Entendemos que este insight señalado por la historiadora británica ha revitalizado la agenda de la historia social del trabajo al inspirar nuevas claves analíticas, preguntas y problemas de estudio. Denotar que las clases sociales son formadas por sujetos sexuados posibilitó, entre otras cuestiones, desesencializar a esos sujetos y sus prácticas, poniendo de relieve la multiplicidad de espacios sociales y dimensiones que gravitan en la experiencia obrera. También advirtió la trascendencia de las rela- 
ciones familiares y comunitarias en la construcción de su identidad y su cultura, los lazos afectivos y los ámbitos de sociabilidad que hacen a la vida cotidiana y a la edificación de los vínculos de camaradería. Asimismo, puso en evidencia las diversas formas de trabajo que convivian (y aún lo hacen) bajo el capitalismo, excediendo a las asalariadas, pero nodales para su reproducción, tales como las relativas al cuidado o la atención familiar llevadas a cabo por las mujeres generalmente.

Como observan otros balances, esta renovación historiográfica se concentró fundamentalmente en la primera mitad del siglo XX (Lobato, 2010; Andújar, 2017; Scheinkman, 2019). Sin embargo, la investigación de la clase trabajadora con perspectiva de género en el lapso comprendido por los últimos cincuenta años viene teniendo una presencia cada vez más elocuente, de la mano de historiadoras comprometidas tanto con el feminismo como con las demandas de verdad, juicio y castigo a los responsables militares y civiles del terrorismo estatal en la Argentina. Argumentaremos aquí que este trazado historiográfico favoreció el retorno del concepto de clase al ruedo de la historia social. Desplazada a la marginalidad de las pesquisas históricas al ritmo del incremento de la desocupación, el supuesto fin de la historia y la lucha de clases en los años 90 del siglo pasado, la clase viene recuperando un lugar importante en el campo de la historia social, revitalizando sus análisis en función de los cruces con los estudios de género y la transversalización estimulada desde este espacio intelectual.

Como señalamos, el recorrido de este balance comprende los últimos cincuenta años de la historia argentina, tomando como punto de partida la segunda mitad de la década de 1960 y como cierre, la primera década de la actual centuria. Conscientes de la inestabilidad en la que se mantiene toda pretensión de demarcar temporalmente las fronteras de la historia reciente, esta periodización se justifica en la dinámica del conflicto de clases, situando su apertura en las luchas portuarias y de los ingenios azucareros tucumanos contra las medidas iniciales de la dictadura militar encabezada por Juan Carlos Onganía. Tanto unas como otras involucraron fuertemente a las comunidades en las que estaban insertas esas actividades y, con ello, a las mujeres, quienes además fueron duramente reprimidas durante el transcurso de las protestas. Concluye esta revisión la primera década del siglo XXI con los nuevos derroteros augurados por la convocatoria del primer paro de mujeres en octubre de 2016, expresión y a su vez cauce de un conjunto de procesos sociales cuya heterogeneidad, marcada por las prácticas y reivindicaciones de mujeres, movimientos feministas y de diversidad sexual, escapa a las posibilidades de este texto.

El derrotero de estas páginas se organiza en dos secciones. La primera aborda los aportes historiográficos más significativos sobre la actuación 
de la clase trabajadora durante los años 60 y 70, enfatizando en las puebladas y la construcción de las corrientes clasistas, por un lado, y las respuestas ante la ferocidad represiva desatada durante la última dictadura militar, por el otro. La segunda se detiene en el lapso comprendido entre los años 80 y la primera década del actual siglo, repasando los procesos de privatización estatal y cierres de fábricas; el devenir de los movimientos de personas desocupadas y la participación sindical de las trabajadoras y sus vinculos con las organizaciones feministas, tres tópicos que concentran la atención de los estudios hasta el momento. Cierran el texto algunas reflexiones que retoman sintéticamente las principales contribuciones de los cruces entre las categorias de clase y de género para la historia social de la clase trabajadora argentina en tiempos recientes.

\section{De las puebladas obreras y populares a la última dictadura militar: un pasado para las mujeres}

La historiografia argentina abocada al estudio de la clase trabajadora siguió con detenimiento los acontecimientos clave en los que ésta estuvo inmersa en la segunda mitad del siglo XX. Fueron el Cordobazo, el clasismo y la represión de la última dictadura militar los procesos que suscitaron mayor interés, afianzando incluso las simientes de un nuevo campo de estudios del pasado reciente. La profusión de pesquisas sobre estos temas, sin embargo, no fue explorada bajo variables analíticas de género sino hasta hace poco tiempo atrás.

Si bien la articulación entre los estudios de género y de clase para los años 60 y 70 es aún incipiente, muestra algunos hallazgos interpretativos. En primera instancia, el ingreso masivo de mujeres de sectores medios al mercado de trabajo ayudó a desnaturalizar su pertenencia al ámbito doméstico y reveló su presencia en ramas de la producción que hasta ese momento habian sido consideradas excluyentemente masculinas como las de las industrias automotrices, navales y gráficas, líderes, por otra parte, de los procesos de renovación sindical de esos años. En segunda instancia, denotó, en esta coyuntura de fuerte radicalización política y sindical, los modos diferenciados en los que varones y mujeres desarrollaron estrategias, repertorios de confrontación y formas organizativas para defender o ampliar sus derechos.

Trazar un panorama actual de esta perspectiva historiográfica muestra, asimismo, una característica sustantiva de su desarrollo que es su carácter federal. Un aspecto que acompaña con mayor consistencia, además, el decurso de los propios fenómenos históricos del periodo. En tal sentido, uno de los hechos importantes que ha sido analizado y en el que las mujeres tuvieron una peculiar gravitación fue el que 
se desarrolló en la provincia de Tucumán cuando en 1966, durante la dictadura de Juan Carlos Onganía, se cerraron numerosos ingenios azucareros. Debe señalarse que, frente a la política de vaciamiento, la clase trabajadora azucarera y sus organizaciones sindicales -en particular la Federación Obrera de Trabajadores de la Industria Azucarera-, pusieron en marcha un plan de lucha que contempló diversos tipos de medidas. Movilizaciones, paros, ollas populares tomaron parte en esta dinámica confrontativa, en la que las mujeres, a su vez, jugaron un rol importante no tan solo para sostener las protestas cocinando para todos y marchando con todos, sino también enfrentando las respuestas represivas del Estado. En medio de uno de esos enfrentamientos en el ingenio de Bella Vista, en 1967, fue asesinada Hilda Guerrero de Molina, militante de la Rama Femenina del Partido Justicialista, trabajadora y esposa de un azucarero desempleado (Nassif, 2017). Estos hechos desataron una pueblada histórica e Hilda se convirtió en un emblema de lucha contra el régimen militar para amplios sectores de la clase trabajadora.

Sin embargo, no fue esta la única ocasión en que las mujeres protagonizaron luchas obreras contra la dictadura poniendo en juego saberes e involucramientos políticos que permitieron, además, ampliar los alcances de la protesta. Así ocurrió durante el largo conflicto que se desató entre los trabajadores portuarios en 1966 frente a las reducciones salariales y la coerción e intervención de sus representaciones sindicales. La intervención de la comunidad en la que habitaban los trabajadores y sus familias, como la de la Villa 31 de Retiro, en la Capital Federal, y en particular el papel jugado por las militantes de la Unión de Mujeres Argentinas (UMA), organismo de masas de filiación comunista, estimuló la aparición de las "Comisiones de Resistencia", y el sostenimiento de la protesta (Snitcofsky, 2011). Esos resortes comunitarios volvieron al ruedo en el noroeste de la Argentina, a propósito de la conocida insurrección del Tucumanazo en noviembre de 1970, cuando las y los estudiantes, trabajadores no docentes y azucareros, junto con vecinos y vecinas rechazaron la política de intervención en las universidades y el cierre de nuevas fuentes de trabajo (Nassif, 2011). Y también durante el Mendozazo de 1972, que tuvo en el centro del conflicto a maestras y trabajadoras de los viñedos, esposas de los contratistas cuyas labores hasta ahí habían quedado invisibilizadas bajo el rótulo de la "ayuda familiar" (Rodríguez Agüero, 2014 y 2017).

Si bien es preciso contar con más investigaciones, al inquirir por las mujeres, los motivos y formatos de su participación colectiva y el horizonte de su involucramiento político y sindical, se reponen sus historias como parte sustantiva de la clase trabajadora. Y van dejando atrás las miradas que las condenaban a quedar subsumidas en las categorias de trabajo familiar o que las ocultaban detrás de censos que carecían de va- 
riables para cuantificar debidamente los trabajos de carácter transitorio en los que eran empleadas. También, denotan la importancia de bucear en las relaciones y prácticas politicas gestadas fuera de los lugares de trabajo, en las comunidades, en los barrios o en los poblados a la hora de analizar el devenir de los numerosos conflictos.

La perspectiva de género anima a repensar, además, las periodizaciones que situaron al Cordobazo como único punto de inflexión de las puebladas, en función de la construcción de una tradición fuertemente masculina y urbana. En tal sentido, los hechos que tuvieron lugar en Tucumán en 1967 muestran que las resistencias contra el gobierno de Onganía comenzaron mucho antes y permiten trazar genealogias mucho más acabadas en las que se reponen las prácticas políticas de las mujeres -y no sólo las de los varones-, para la comprensión del pasado reciente. A su vez, colabora en devolver a las movilizaciones anteriores a mayo de 1969 su propia especificidad histórica. Sin quitar trascendencia al Cordobazo, se vuelve factible situar tales experiencias de radicalización obrera en un mapa mucho más amplio y en una trama social mucho más abarcativa al indexar a las mujeres que, además de ser trabajadoras, comportaban compromisos políticos o sindicales.

Pero también hay cuestiones nuevas que esta historiografia generizada ha aportado alrededor de este hecho histórico. Si bien el Cordobazo fue ampliamente visitado por la literatura académica y política, solo recientemente, y en el marco de la agenda pública de los feminismos, se delinearon nuevas preguntas relativas al rol de las mujeres obreras y de los sectores medios en su devenir. En primera instancia se ha matizado el carácter mayoritariamente masculino atribuido a la movilización porque se pudo advertir la participación de trabajadoras de distintas industrias y del área de servicios, así como también la de estudiantes y profesionales (Noguera, 2019), tal como quedó registrado en un libro de divulgación que reúne fotografias y testimonios de mujeres (Fulchieri, 2018). Otro tanto sucede con las experiencias de organización y de lucha profundamente anudadas a este proceso de movilización como el fenómeno del clasismo. Algunas investigaciones llamaron la atención sobre la adhesión a esta corriente sindical en actividades industriales tradicionales, cuya fuerza laboral era dominantemente femenina, como en el caso de algunas empresas cordobesas del calzado y del vidrio (Ortiz, 2019) o las vinculadas a ramas dinámicas, como por ejemplo la Industria Latinoamericana de Accesorios S.A. (ILASA). Esta participación de las mujeres en conflictos destituyentes de las direcciones burocráticas propiciando repertorios de lucha como el de las ocupaciones de fábrica, el uso de armas caseras o el ejercicio de la democracia obrera directa se hizo visible también en la inclusión de demandas propias del género femenino y en los pliegos de reivindicaciones, tales como el rechazo a 
la segmentación y jerarquización de las categorías laborales y salariales en favor de los varones, contra el ejercicio de abuso de poder de los capataces y por la creación de instancias de cuidado infantil en la misma planta (Laufer, 2019).

La activa presencia de las trabajadoras fue auscultada, asimismo, para la industria gráfica, donde las mujeres alcanzaron a ser por ese entonces el $20 \%$ de la fuerza de trabajo. Su estudio develó que el incremento de su presencia en las listas electorales de las agrupaciones gremiales tuvo relación con la renovación generacional del activismo obrero. De tal modo, los embates librados por las jóvenes trabajadoras contra la vieja guardia sindical peronista fortalecieron una mayor gravitación de los sectores combativos a la par que modificaron la agenda del gremio a partir de demandas propias del género femenino como la igualdad de salario ante la misma tarea o la exigencia de recategorizaciones, ascensos y apertura de especialidades laborales tradicionalmente solo aptas para varones (Ghigliani, 2018). Estas trazas interpretativas se replican en estudios sobre actividades tan diversas como las relativas al servicio doméstico, en particular respecto de las presentaciones judiciales en pro de demandas por derechos (Pérez, 2014), en la industria textil en Trelew (Gatica, 2000) o en la industria del pescado de Mar del Plata donde las trabajadoras llevan adelante conflictos gremiales a la luz de sus adscripciones político-sindicales (Ruocco, 2010). La introducción de la noción de comunidad que entrama esta actividad ha posibilitado recuperar no sólo las prácticas confrontativas y su urdimbre sino también el impacto de las representaciones que sus pares varones -compañeros de trabajo, esposos, activistas sindicales y militantes políticos-, construyeron sobre ellas y sobre lo femenino en el trabajo del pescado (Laitano y Nieto, 2019).

Otro núcleo temático destacable para este período toma cuerpo durante los conflictos laborales desatados entre 1973 y 1975. Se trata de los casos de Propulsora Siderúrgica y de Astilleros Río Santiago, industrias dinámicas ubicadas en la provincia de Buenos Aires (Barragán y Rodríguez, 2012). Alli las preguntas que guian los análisis bucean en la construcción de las masculinidades obreras y su incidencia tanto en el proceso productivo como en las formas de organización y de lucha protagonizadas por estos trabajadores en una etapa de intensa actividad represiva estatal y paraestatal. En esta clave se escudriñan también las disputas que tuvieron lugar en esas formas de concebirse varón trabajador a partir de diferencias generacionales, del lugar ocupado en el proceso de trabajo y de las destrezas o habilidades requeridas para cada tarea productiva (Brandolini, 2019). A su vez, se explora la vigencia del ideal del varón proveedor y los alcances de su cuestionamiento por parte de las propias mujeres de la clase trabajadora, sondeando en qué medida 
el proceso de radicalización de clase facilitó o no el cuestionamiento de las relaciones de género, así como la emergencia de nuevas formas de imaginar(se) como trabajadores y como varones obreros.

La represión desatada en la última dictadura militar contra la clase trabajadora está siendo objeto de algunas investigaciones interesadas en reconstruir el destino de las y los delegados de las comisiones internas, así como los vínculos entre las y los activistas sindicales y las diversas corrientes políticas (Barragán, 2014; Basualdo, 2016). Mas las resistencias y las distintas formas de negociación de las trabajadoras con el régimen militar aún han sido poco exploradas, a excepción de algunos conflictos que tuvieron lugar en la rama textil, como en el caso de Alpargatas en 1979, año por otro lado de la primera huelga general contra la dictadura (Mitidieri, 2014).

La diversificación en el conocimiento sobre las formas en que el Estado llevó adelante la represión durante los años 60 y 70 tuvo un correlato en investigaciones que pusieron el acento en la legalidad jurídica con la que operaron tanto gobiernos constitucionales como de facto. Y en tal sentido, cómo las trabajadoras y trabajadores estatales, por ejemplo, se convirtieron en foco de una purga política a partir del uso de distintos instrumentos o de figuras laborales expulsivas como las bajas, cesantias, suspensiones y renuncias forzadas, oficiando, en oportunidades, como antesala de la desaparición forzada. La retórica maternalista del régimen militar no alcanzó a las mujeres embarazadas que por su condición de activistas sindicales o políticas fueron primero despedidas y luego desaparecidas (D’Antonio, 2018).

Los estudios hasta aquí señalados han amplificado los sentidos del pasado reciente. Y no tan solo porque hasta hace poco tiempo atrás este había sido auscultado en términos de violencia política y de represión estatal. También porque el ejercicio de poner en foco a las mujeres ha mostrado otras inflexiones y posibilidades interpretativas, tal como creemos haberlo mostrado, en los hechos, en las periodizaciones y en las dinámicas políticas.

\section{Trabajadoras, piqueteras, sindicalistas y feministas en la Argentina neoliberal}

El proceso desatado con la profundización del modelo neoliberal y sus efectos sobre la vida de las y los trabajadores ha sido hasta ahora escasamente atendido por las investigaciones históricas. A diferencia de lo ocurrido en otras disciplinas, como la sociologia, la antropología o la demografia, cuyas producciones son más profusas, los estudios inscriptos en la historia social del trabajo con perspectiva de género conforman un universo mucho menos abultado. Esa exigüidad no se replica, sin embargo, en lo que refiere a tópicos, problemas y abordajes 
teórico-metodológicos propuestos para examinar el devenir de la clase trabajadora entre los años 80 del siglo pasado y lo que va del actual. En ese plano, esta agenda historiográfica despunta sus avances con densidad, atreviéndose a traspasar límites temporales que hasta hace poco resultaban prácticamente infranqueables para el quehacer disciplinar. El desarrollo dispar de las investigaciones que la conforman respecto de territorialidades, actividades productivas o conflictos examinados impide igualmente obtener sintesis interpretativas amplias sobre el periodo. Pero entre sus trazas es posible reconocer ciertas preocupaciones dominantes, articuladas en función de temas cardinales para la comprensión de ese pasado, como el referido a las condiciones de trabajo bajo el auge neoliberal y su crisis, las formas de organización y de lucha ante su persistente y violenta vulneración de derechos, las experiencias organizativas de las y los desocupados, el decurso de sus protestas o el horizonte de sus demandas.

Esas preocupaciones vertebran el balance comprendido en esta sección, cuya revisión se despliega alrededor de tres ejes problemáticos que concentran la atención hasta el momento: la privatización de las empresas públicas y el cierre de fábricas, la aparición de novedosas organizaciones y repertorios de protesta colectiva entre las y los desocupados $y$, finalmente, el incremento del activismo sindical de las trabajadoras y sus vínculos con las organizaciones feministas.

El primero de estos ejes reúne investigaciones focalizadas en las reacciones de la clase trabajadora ante la privatización de las empresas estatales y las medidas de racionalización laboral implementadas bajo las administraciones menemistas. Interesadas en explorar no sólo lo sucedido en los espacios laborales sino también en el ámbito familiar y comunitario en tanto territorios centrales de la experiencia obrera, estas investigaciones pusieron de relieve en las respuestas colectivas a la embestida neoliberal unas tradiciones de organización, de lucha y de elaboración de demandas y reivindicaciones que tuvieron en la familia proletaria y en los lazos comunitarios sustentos fundamentales. Tal lo ocurrido en el sector ferroviario, donde la participación de las mujeres y de las familias que habitaban en las comunidades forjadas en torno a los rieles animó confrontaciones que desafiaron la complacencia de las dirigencias sindicales con el gobierno menemista, recuperando, asimismo, experiencias de lucha muy anteriores, desarrolladas en tiempos de la presidencia de Arturo Frondizi y su plan de Conmoción Interna del Estado (Agostini, 2018; Corsi, 2019). Otro tanto sucede con respecto al sector telefónico. Junto con el ferrocarril, la telefonía, que congregaba a su vez una gran cantidad de mujeres entre su fuerza laboral, constituyó la punta de lanza del proceso privatizador de inicios de la década de 1990. Al igual que la comunidad ferroviaria, las y los 
telefónicos desataron una extensa huelga contra la política menemista que contradijo la complicidad de un sector de la dirigencia sindical. El estudio de este proceso se situó en los efectos materiales y simbólicos provocados por la privatización, con la ruptura del imaginario centrado en "la gran familia telefónica" (Davolos, 2001). Pero también, en ciertas reconstrucciones sindicales ocurridas posteriormente, como la del Sindicato de los Profesionales de las Telecomunicaciones, resultado en buena medida de las iniciativas de un grupo de mujeres trabajadoras de este sector (Facio, 2019).

Las respuestas de la clase trabajadora, con sus iniciativas contenciosas y los retos que implicaban a la complacencia de las dirigencias sindicales hacia las medidas neoliberales, fueron examinadas por su parte a propósito de la flexibilización laboral y en demanda del mantenimiento de las fuentes de trabajo. Especial interés concitó la rama textil, actividad con una elevada proporción de mujeres en su fuerza laboral y duramente castigada por la apertura comercial y financiera auspiciada por el ex ministro de Economía Domingo Cavallo en 1991. Su estudio permitió advertir la manera en que las desigualdades de género gravitaron en este proceso, implicando una mayor explotación de las trabajadoras que la de sus pares varones ${ }^{1}$ y el quebrantamiento de solidaridades de clase en materia de posibilidades de acceso a la representación sindical o en cuanto a la dinámica de los conflictos, como sucedió en el taller textil Confecciones Patagónicas del parque industrial de Trelew, uno de los más importantes del país (Saso, 2016).

Otra experiencia visitada en esa compleja trama es la de las fábricas recuperadas. Entendidas como una forma específica de demanda por la fuente de trabajo consistente en la ocupación y autogestión de las empresas por parte de las y los trabajadores (Fernández Álvarez y Partenio, 2010), su análisis comprende tópicos, entre los que se cuentan las mudanzas provocadas por esta experiencia en significados del trabajo para las mujeres involucradas, en la distribución de sus tiempos cotidianos, en las demandas relativas a sus intereses de género (recuperando la clásica distinción establecida por Maxine Molyneux y Temma Kaplan), en los entrecruzamientos entre sus actividades productivas y sus iniciativas de protesta. ${ }^{2}$ Presentes en varias regiones de la Argentina y entre actividades productivas tan diversas como la alimentación, textil,

1. Vale la pena recordar que el deterioro de las condiciones de trabajo asalariado en esta fase del capitalismo ha favorecido el ingreso de las mujeres al mercado laboral en condiciones de mayor opresión que en momentos anteriores, situación a la que se indexa el incremento de la carga de su trabajo reproductivo debido al retiro del Estado de las actividades de protección social.

2. Para un repaso exhaustivo sobre estas producciones, véase Arriaga y Medina (2018). 
metalúrgica o ceramista, los estudios sobre la recuperación de empresas denotan en especial los cambios producidos en la identidad de clase y de género entre sus protagonistas, dando lugar en ocasiones a una mayor democratización de ciertas prácticas obreras y a la emergencia de ámbitos de organización específicos para las mujeres involucradas, como se observó en el caso de la ceramista Zanón (Freire, 2008).

Esta participación femenina es objeto fundamental de los estudios que integran el segundo eje problemático de esta sección, situado en torno a las formas de organización surgidas entre los y las desocupadas especialmente a partir de la década de 1990. Entre ellas, un lugar preponderante lo ocupan los movimientos piqueteros y la principal herramienta de confrontación utilizada por este actor, los cortes de ruta. Situados con fuerza en el centro de la escena política nacional a partir de las puebladas neuquinas de 1996, el estudio de esta práctica beligerante que se fue diseminando por diversas geografias de la Argentina, así como de las organizaciones que nuclean a personas desocupadas -bajo diversas nominaciones y horizontes políticos-, puso de relieve el protagonismo de las mujeres en la gestación de los movimientos piqueteros y las múltiples experiencias politicas que portaban muchas de ellas y que nutrieron sus decisiones de salir colectivamente a las rutas asi como la manera en que lo hicieron (Partenio, 2012; Andújar, 2014; Díaz Lozano, 2015;). Al seguir las huellas de sus acciones y de las demandas en que se sostuvieron, algunas pesquisas exploraron asimismo la emergencia de ámbitos estrictamente femeninos dentro de las organizaciones piqueteras, sus vínculos con partidos políticos y sectores del feminismo, las redefiniciones de sus identidades politicas así como de las redes en que se involucran, de sus relaciones entre sí y con los varones dentro y fuera de los movimientos piqueteros (Cross y Partenio, 2011; Partenio, 2012; Andújar, 2014). También se examinó, como parte de estas acciones beligerantes encabezadas por mujeres desocupadas, su participación en las tomas de sedes de instituciones gubernamentales y de empresas, así como en las movilizaciones callejeras, exigiendo recursos que permitieran garantizar la reproducción de sus comunidades (Auzoberría et al., 2018). ${ }^{3}$

El tendido de puentes con las organizaciones feministas integra el último eje planteado aquí, orientado a reseñar los aportes de las producciones dedicadas a la participación sindical de las trabajadoras.

En un estudio reciente, Arriaga y Medina (2018) pasan revista a la

3. Otro colectivo integrado por mujeres es el que remite al mundo rural y a las movilizaciones lideradas por el Movimiento de Mujeres Agropecuarias en Lucha (Giarraca y Teubal, 2001), cuyas luchas ganaron trascendencia bajo el menemismo, pero no así, lamentablemente, entre las historiadoras sociales. 
literatura interesada en las relaciones entre trabajadoras y sindicalismo, tematizando las preocupaciones sobresalientes alrededor de tres cuestiones: la participación de las mujeres en las organizaciones sindicales, la institucionalización de una agenda de género en el mundo sindical y las acciones reivindicativas o contenciosas de las trabajadoras organizadas. Como consignan ambas autoras retomando trabajos previos, la presencia femenina en los sindicatos no es una novedad de la historia reciente. Mas en los años inmediatamente posteriores al ocaso de la última dictadura militar, esta presencia ganó otra visibilización en consonancia con un movimiento feminista y de mujeres que se impuso con más vehemencia en el escenario político nacional, concitando la inclusión de algunas de sus demandas y preocupaciones en la agenda gubernamental despuntada desde el gobierno radical (Barrancos, 2007).

Algunas pesquisas situadas en esta problemática rastrean las demandas que las trabajadoras formularon en el seno de sus organizaciones sindicales, su concreción y gravitación en el reconocimiento de mayores derechos laborales, en la democratización de las estructuras sindicales y en la conformación de una agenda de género capaz de propiciar una mayor equidad entre mujeres y varones en el mundo laboral (Arriaga y Medina, 2020; Aspiazu, 2014). Otros trabajos indagaron el incremento de las tasas de afiliación femenina, la creación de espacios institucionales específicos dentro de los sindicatos y sus alcances -en particular con la creación de las secretarias de la mujer y/o de género-, así como su incidencia en ciertas modificaciones legislativas en procura de una mayor equidad de género a nivel representativo, como en el caso de la Ley de Cupo Sindical Femenino sancionada en 2002 (Arriaga y Medina, 2020; Bonacorsi y Carrario, 2012)

Entre esas pesquisas, los sindicatos que reúnen a trabajadoras de actividades tradicionalmente feminizadas, como por ejemplo maestras y docentes de escuelas medias, fueron examinados ampliamente, sobre todo a la luz de la extensa duración de muchos de sus conflictos y las alianzas sociales que movilizaron en ellos -como en el caso de la "Marcha Blanca" bajo el alfonsinismo y de la Carpa Blanca levantada en la Plaza de los Dos Congresos en 1997- o la dureza de las represiones que recibieron, con su saldo de asesinados por las fuerzas de seguridad, como en el caso de Teresa Rodríguez en 1997 o de Carlos Fuentealba diez años más tarde, ambos ocurridos durante protestas en la provincia de Neuquén (Aiziczon, 2009; Andújar, 2014). ${ }^{4}$ Algunas exploraciones se interesan por los significados que adquiere el ejercicio de esta actividad y sus empeños dentro del ámbito universitario. A la luz de los itinerarios

4. Para un repaso sobre la vastedad de las producciones interesadas en el mundo sindical docente en la Argentina reciente, véase Arriaga y Medina (2018). 
laborales, los escalafones, las estructuras de cátedra y las nociones de prestigio que rodean su ejercicio, estas pesquisas rastrean los conflictos que atraviesa esta labor en función, entre otras cuestiones, de una percepción que la sitúa a medio camino entre una profesión y un trabajo (Lozano Rubello, 2019).

Por otro lado, se ha comenzado a historiar agremiaciones más novedosas, como aquellas que reúnen a las trabajadoras del mercado del sexo, rastreando en su configuración ciertas derivas de las nociones y definiciones de trabajo que sus protagonistas inscriben en tal actividad. Un caso paradigmático en tal sentido lo constituye la Asociación de Mujeres Meretrices de la Argentina, integrada a la Central de Trabajadores de la Argentina (Sayus, 2013).

Las relaciones entre la militancia feminista y el activismo sindical femenino conforman una arista central de este eje. Diversas investigaciones se ocupan de explorar los espacios de encuentro, de transferencia de saberes y las prácticas conjuntas llevadas a cabo por mujeres de uno y otro colectivo. Sin dudas, entre esos espacios de reunión e intercambio, los Encuentros Nacionales de Mujeres ocupan un lugar central no sólo por su pervivencia en el tiempo y las posibilidades de debate que habilitan entre miles de mujeres (Masson, 2007). También por las transformaciones que tuvieron lugar en los talleres de discusión a partir de la incorporación de temáticas relacionadas con debates sociales y gremiales (Viano, 2014). Estos diálogos entre activistas sindicales y feministas no sólo posibilitan acciones conjuntas o confluencias de banderas de lucha en determinadas circunstancias, sino también la elaboración de novedosas demandas, propuestas y conceptualizaciones alrededor de los significados del trabajo femenino productivo y reproductivo, su importancia social y las nociones de valor que los sustentan. Entre estas prácticas comunes, los paros de mujeres adquieren cada vez mayor resonancia al dejar explicitado justamente el contenido de trabajo de las tareas de cuidado. Asimismo, ello viene enriqueciendo la agenda de los estudios de la historia social del trabajo a partir del tendido de puentes con la economía feminista y las nociones que la amparan.

Para cerrar, deseamos llamar la atención sobre los esfuerzos metodológicos que conlleva el estudio de la historia reciente de la clase trabajadora argentina en clave de género pues implica poner en juego diversas estrategias para abordar ciertas fuentes o descubrirlas allí donde pareciera no haber nada. Y en esos empeños, la historia oral adquiere un lugar preeminente, sustentándose en elaboraciones interesadas en generizar las memorias, los relatos y las interpretaciones sobre el pasado, como lo han denotado variadas investigaciones (Jelin, 2001; James, 2004; Viano, 2008; Andújar, 2014). 


\section{Conclusiones}

Tan solo poco tiempo atrás, señalábamos en un estado del arte sobre el vínculo entre el campo de estudios del pasado reciente y el de los estudios de género, que su articulación con la historia social de la clase trabajadora se hallaba en verdadera vacancia (D'Antonio y Viano, 2018). El repaso llevado a cabo en este artículo muestra que las producciones que cruzaron clase y género para esta etapa se hallan actualmente en proceso de maduración. Los debates sociales efectivamente han impactado sustantivamente en el ámbito académico. Y es la marea verde la que nos ha permitido estimular y en tal caso hoy en día brindar un panorama actualizado de los temas, problemas y nuevos debates planteados.

La mayoría de los trabajos que aquí consignamos tienen como preocupación dar a las mujeres un lugar preponderante en tanto sujeto de análisis, animados por las formas y los contenidos que asumen las desigualdades de poder entre los y las trabajadoras, o las nociones de masculinidad y de feminidad que gravitan en el mundo laboral. Incluso este encuadre ha facilitado el despunte de algunos estudios que han comenzado a enfocarse en sujetos no heterosexuales, aunque todavia nos digan poco sobre la manera en que ello se anuda con la pertenencia de clase y con el mundo del trabajo.

La articulación de estas perspectivas permite advertir una historia repleta de personas que, miradas a ras del suelo, nos devuelven imágenes más nítidas sobre esas mujeres y varones trabajadores que vivieron estos tiempos convulsivos. También nos deja entrever cómo intentaron modificar, mejorar o revolucionar las condiciones materiales de existencia en las que les tocó vivir, cómo se organizaron y confrontaron con sus adversarios de clase para establecer sus demandas por derechos, cómo construyeron sus identidades, sus lazos afectivos y sus ámbitos de sociabilidad. Los hallazgos interpretativos aquí reseñados desestabilizaron, además, las nociones clásicas de trabajo ya que pusieron en evidencia la coexistencia tensa entre formas de trabajo asalariadas y reproducción doméstica. En esa dirección, develaron que tales variables y categorias no son asexuadas y que la idea de neutralidad no ha hecho más que confundir la preferencia por la objetividad con la experiencia enteramente masculina de este sector de clase.

Nuestra propia reflexión, aún abierta, no buscó respuestas conclusivas sino más bien mapear terrenos fértiles en los hallazgos de la interpretación. Incluso, somos conscientes de que hay numerosos acontecimientos centrales, como la huelga de la Ford de 1985 o la de Villa Constitución en 1991, que no fueron debidamente contados en una clave generizada. No obstante, creemos que los esfuerzos hasta aquí realizados renuevan la agenda historiográfica y la refinan. Es cuestión 
de tiempo, de echar a rodar con más fuerza un movimiento que ya tiene bases sólidas y que cada vez cuenta con más adhesiones entre las investigadoras. La suma de retazos con los que contamos está impactando poco a poco en las dinámicas más generales del conocimiento sobre la historia social de la clase trabajadora argentina, encarnada en mujeres y varones reales, de los últimos 50 años.

\section{Referencias}

Agostini, L. (2018). La comunidad ferroviaria de Laguna Paiva durante la huelga nacional de 1961. Sociabilidades, identidades y prácticas. Tesis de Maestría, Universidad Nacional de Quilmes.

Aiziczon, F. (2009). La revuelta de los corpiños. Performance, activismo feminista y lucha sindical docente en Neuquén. Mora, 15, 1, 17-33.

Almada, D. (2019). Mujeres trabajadoras rurales: experiencias de vida y luchas politicas en la Formosa de los años 70. A cincuenta años del Cordobazo. Repensando el ciclo de protestas obreras, rebeliones populares $e$ insurrecciones urbanas. Facultad de Filosofia y Humanidades, UNC.

Andújar, A. (2014). Rutas argentinas hasta el fin... Mujeres, politica y piquetes (1996-2001). Luxemburg.

Andújar, A. (2017). Historia social del trabajo y género en la Argentina del siglo XX: balance y perspectivas. Revista Electrónica de Fuentes y Archivos, 8, 8, 43-59.

Arriaga, A. y Medina, L. (2018). Desafios de las organizaciones sindicales frente a la desigualdad de género. Hacia la construcción de una agenda de investigación. http://fh.mdp.edu.ar/revistas/index.php/pasadoabierto.

Arriaga, A. y Medina, L. (2020). Activismo de género en las organizaciones sindicales. Reivindicaciones y estrategias emergentes en los Encuentros Nacionales de Mujeres. Trabajo y Sociedad, 34, XXI, 155-178.

Aspiazu, E. (2014). Equidad de género, mercado de trabajo y sindicalismo en Argentina. Realidad Económica, 284, 10-36.

Auzoberría, M. et al. (2018). Las tomas de Termap. En P. Becher y G. Pérez Álvarez (comps). Las organizaciones de trabajadores desocupados en la historia reciente de Argentina: Experiencias, luchas y esperanza (19902015) (pp. 197-226). CEISO.

Barragán, I. (2014). Matilde Itzigsohn, violencia y represión: trayectoria sindical de base en una fábrica de hombres, el Astillero Río Santiago (1973-1976). Amerika: Mémoires, Identités, Territoires, 11, 1-9. http:// hdl.handle.net/11336/52092.

Barragán, I. y Rodríguez, F. (2012). Clase, género, politización y violencia. Los casos del Astillero Río Santiago y Propulsora Siderúrgica 1974-1975. http: / estudiosmaritimos.files.wordpress.com/2014/01/rems-nc2ba-5-6-dossier-gc3a9nero-y-clase-barragc3a1n-y-rodrc3adguez.pdf. 
Barrancos, D. (2007). Mujeres en la sociedad argentina. Una historia de cinco siglos. Sudamericana.

Basualdo, V. (2016). Militancia y organización obrera de base durante la primera mitad de los años 70: una aproximación desde la historia oral al caso de Alpargatas en Florencio Varela. En K. Grammático (comp.) Historia reciente, género y clase trabajadora: Cinco estudios para pensar un problema de investigación (pp. 9-30). UNAJ.

Bonaccorsi, N. y Carrario, M. (2012). Participación de las mujeres en el mundo sindical: Un cambio cultural en el nuevo siglo. http:/ / www.scielo.org. ar/scielo.php?script=sci_arttext\&pid=S1669-57042012000100007\&ln$\mathrm{g}=$ es\&nrm=iso. $\mathrm{F} / \mathrm{c}: 21 / 6 / 2017$.

Brandolini, C. (2019). Los obreros de Fiat Concord Sauce Viejo en los días del "rodrigazo": conflicto y represión. V Taller Historia Social, Género y Derechos. Grupo de Trabajo, Historia Social y Género.

Corsi, M. (2019). Rieles en lucha. Una aproximación histórica a la huelga de 1991 en la comunidad ferroviaria de Victoria, provincia de Buenos Aires. V Taller Historia Social, Género y Derechos. Grupo de Trabajo, Historia Social y Género.

Cross, C. y Partenio, F. (2011). ¿Cuál cambio social? Construcción de vínculos políticos en un espacio de mujeres piqueteras. https://revistapuntogenero.uchile.cl/index.php/RPG/article/view/16861/17561.

D'Antonio, D. (2018). Bajas, cesantías, suspensiones y renuncias forzadas: trabajadores y trabajadoras estatales bajo la mira (Argentina: 1973-1983). En D. D’Antonio (comp.). Violencia, espionaje y represión estatal. Seis estudios de caso sobre el pasado reciente argentino (pp. 59-91). Imago Mundi.

D’Antonio, D. y Viano C. (2018). A propósito de la historia reciente, la historia de las mujeres y los estudios de género. En G. Águila, L. Luciani, L. Seminara y C. Viano (comps). La historia reciente en Argentina. Balances de una historiografía pionera en América Latina (pp. 19-38). Imago Mundi.

Davolos, P. (2001). Después de la privatización: trayectorias laborales de trabajadores con retiro voluntario. Estudios del Trabajo, 21, 69-94.

Díaz Lozano, J. (2015). Movimiento en Femenino. Trayectorias de vida de mujeres que participan en organizaciones populares. En A. Nateras Dominguez, G. Medina Carrasco y M. Sepúlveda Galeas (coords.). Escrituras emergentes de las juventudes Latinoamericanas. Gedisa.

Facio, M. (2019). Experiencias laborales y gremiales de las mujeres del Sindicato de los profesionales de las telecomunicaciones (Cepetel) (19892010). V Taller Historia Social, Género y Derechos.

Fernández Álvarez, M. y Partenio, F. (2010). Empresas recuperadas en Argentina: producciones, espacios y tiempos de género. Tabula Rasa, $12,119-135$.

Freire, A. (2008). La participación de las mujeres en las fábricas recuperadas: el caso de la Cerámica Zanón, Neuquén 2000-2006. En P. Navarro Floria (comp.). Historia de la Patagonia: 3ras. Jornadas (CD-Rom). 
Fulchieri, B. (2018). El Cordobazo de las mujeres. Las Nuestras.

Gatica, M. (2000). Industrialización, proletarización y subproletarización. ¿Una nueva identidad para la mujer en Trelew? Proyecto de investigación, informe final UNPSJB, Secretaría de Ciencia y Técnica, Trelew.

Ghigliani, P. (2018). Las mujeres trabajadoras en la industria gráfica de los años sesenta y setenta: participación sindical, agencia contenciosa y discursos de género. Trabajo y Sociedad. http://www.memoria.fahce. unlp.edu.ar/art_revistas/pr.8960/pr.8960.pdf.

Giarraca, N. y Teubal, M. (2001). El movimiento de Mujeres Agropecuarias en Lucha. En N. Giarraca et al. (comp.). La protesta social en la Argentina. Trasformaciones económicas y crisis social en el interior del país (pp. 737-762). Alianza.

Hall, C. (2013). La historia de Samuel y Jemima: Género y cultura de la clase trabajadora en la Inglaterra del Siglo XIX. http:/ /www.scielo.org. ar/scielo.php?script=sci_arttext\&pid=S1853-001X2013000200005\&ln$\mathrm{g}=\mathrm{es} \& \mathrm{nrm}=\mathrm{iso}>$. Consultado 12 de enero de 2020.

James, D. (2004). Doña María. Historia de vida, memoria e identidad politica. Manantial.

Jelin, E. (2001). Los trabajos de la memoria. Siglo XXI.

Lasalle, A., Lasalle, P. y Di Liscia, M. (2010). Verano del 72. La gran huelga salinera. Memoria, género y politica. Miño y Dávila.

Laitano, G. y Nieto, A. (2019). Muñecas bravas en un nido de ratas. Notas sobre las representaciones masculinas y el protagonismo femenino en las luchas gremiales de la industria del pescado. Ejes de Economía y Sociedad. 3, 4, 56-80.

Laufer, R. (2019). Clase y género en la Córdoba combativa. Las obreras de ILASA y la ocupación de la fábrica en 1970. http:/ / revistas.unc.edu.ar/ index.php/anuariohistoria.

Lobato, M. (2010). Historia del trabajo, género y clase. En: J. Cernadas y D. Lvovich (eds.). Historia, ¿para qué? Revisitas a una vieja pregunta (pp. 208-227). Prometeo.

Lozano Rubello, G. (2019). Espacios de intervención y pertenencia de docentes de la UBA en la actualidad. http://propuestaeducativa.flacso. org.ar/wp-content/uploads / 2019/11/PropuestaEducativa51-articulo-jov-RUBELLO.pdf.

Masson, L. (2007). Feministas en todas partes. Una etnografia de espacios y narrativas feministas en Argentina. Prometeo.

Mitidieri, G. (2014). La huelga de Alpargatas en 1979: las nociones de lo justo en dictadura. Páginas, 6, 2, 83-102.

Nassif, S. (2011). Conflictos sociales protagonizados por obreros y estudiantes en Tucumán durante 1970. Conflicto Social, 4, 5, 175-200.

Nassif, S. (2017). Resistencia obrera y popular en Tucumán en los inicios de la dictadura de Onganía: asesinato de Hilda Guerrero de Molina y la pueblada en Bella Vista. Trabajo y Sociedad, 32, 195-221. 
Noguera, A. (2019). Revoltosas y revolucionarias. Mujeres y militancia en la Córdoba setentista. Editorial de la UNC.

Ortiz, M. (2019). Con los vientos del Cordobazo. Los trabajadores clasistas en tiempos de violencia y represión. Editorial de la UNC.

Partenio, F. (2012). Género y participación política: los desafios de la organización de las mujeres dentro de los movimientos piqueteros en Argentina. En P. Aguilar et al. Las deudas abiertas en América Latina (pp. 245-288).Clacso.

Pérez, I. (2014). Género y derechos laborales: servicio doméstico y trabajo doméstico no remunerado en la Justicia laboral en Argentina (19561974). Páginas, 6, 12, 67-82.

Rodríguez Agüero, L. (2014). Maestras y madres. Género y lucha docente en el post Mendozazo (1972-1973). MILLCAYAC, I, 1, 75-98.

Rodríguez Agüero, L. (2017). ¿Trabajadores o empresarios? La lucha de los contratistas de viña, Mendoza 1969-1976. Revista Electrónica de Fuentes y Archivos, 8, 8, 217-236.

Ruocco, L. (2010). Reivindicaciones de las mujeres obreras de la industria del pescado: una perspectiva de clase y género a partir de los convenios colectivos de trabajo (Mar del Plata, 1942-1975). Revista de Estudios Maritimos y Sociales, 3, 93-104.

Saso, D. (2016). Género, clase, experiencia y conflicto social: la huelga de Confecciones Patagónicas. Theomai, 34, 4-114.

Sayus, A. (2013). El arte de AMMAR: mujeres, mercado del sexo y trabajo en San Miguel, provincia de Buenos Aires. Taller de discusión: “Trabajadores y Sindicalismo". Universidad Nacional de General Sarmiento.

Scheinkman, L. (2019). De la historia politica a los estudios de género: la historiografia sobre el mundo del trabajo de la primera mitad del siglo XX en Buenos Aires. Trabajo y Sociedad, 32, 281-305.

Snitcofsky, V. (2011). Villas de Buenos Aires y conflictos portuarios bajo el gobierno de Onganía: aportes para el análisis de la articulación entre sindicalismo de base y organización territorial. En V. Basualdo (coord.). La clase trabajadora argentina en el Siglo XX: Experiencias de lucha y organización (pp. 51-100). Cara o Ceca.

Viano, C. (2008). Mujeres y movimientos sociales: un acercamiento a Madres de Plaza de Mayo desde una historia de vida. En G. Necoechea Gracia et al. (comps). Historia oral y militancia politica en México y en Argentina (pp. 61-81). El Colectivo.

Viano, C. (2014). Voces (des-encontradas) en los Encuentros Nacionales de Mujeres en Argentina. Páginas, 6, 11, 49-68. 